\title{
Reflections on the Impact of Mental Health Ward Staff Training in Race Equality and Values-Based Practice
}

\section{4}

\author{
Kim Woodbridge-Dodd and Evette A. Hunkins-Hutchinson
}

\subsection{Introduction}

In 2008, following implementation of the UK's 2006 Equality Act, before the UK's Equality Act 2010, the authors undertook a project to evaluate the impact of combining race equality with values-based practice training for staff on an acute inpatient mental health ward. The aim of the project was to see whether training in values-based practice would help staff to embed race equality practice into their work.

One author (Kim) was the operational manager for the ward; the other author (Evette) was the external evaluator for the project. The project was initially scoped out by Kim and three senior ward colleagues (all three were nurses). A steering group was set up comprising of Kim, ward colleagues, the race equality trainer, and Evette. This formed the core membership, with others, such as the regional Delivering Race Equality lead, and an additional qualified nurse from the ward, joining on occasion. The race equality training sessions were run by a national lead in race equality training who was involved in initial discussions about the delivery of both elements of the training, race equality, and values-based practice. They were also aware of the evaluation element but took no part in the evaluation other than to contribute feedback on their experience of running the race equality sessions.

Thirty-four core staff members were offered the training: the mix was 7 men and 27 women; 21 were white, 11 black, and 2 were of mixed heritage. Most were registered mental health nurses and held posts with different levels of responsibility.

K. Woodbridge-Dodd ( $\square$ )

Faculty of Health, Education and Society, University of Northampton,

Northampton, Northamptonshire, UK

E. A. Hunkins-Hutchinson

Faculty of Arts, Humanities and Cultures, University of Leeds, Leeds, UK

(C) The Author(s) 2021

D. Stoyanov et al. (eds.), International Perspectives in Values-Based Mental

Health Practice, https://doi.org/10.1007/978-3-030-47852-0_44 
The staff completed a day-and-a-half race equality training followed by a day-anda-half values-based practice training. To evaluate impact, participants were invited to attend two focus groups, one immediately after the race equality training and one immediately after the values-based practice session. In addition, staff shared their reflections with the evaluator whilst in practice during a 2-day period following the second focus group. Further details of the training and evaluation can be found in the reference at the end of the chapter (see Guide to Further Sources).

We reflect here on the project from our perspectives, respectively, as operational manager (Kim) and external evaluator (Evette), focusing on, (1) early expectations, (2) initial impressions, (3) evaluation and report on findings, (4) thinking back, and (5) what we would do differently. As will be seen, our reflections in some areas coincide and in others diverge. We conclude with a brief section summarising our shared learning points for the future.

\subsection{Early Expectations}

\section{Kim}

Reflecting on my early expectations for the project, I realise how little I knew about the challenges that race equality training could pose for all staff, black, white and all people of colour. At that time, we, the staff of the acute inpatient ward, were feeling very positive. We had just received a rating of 'Excellent' from the Care Quality Commission (the standards regulator for the UK's National Health Service), an award that very few services receive.

This rating endorsed all the dedicated work of staff in improving the experience of people using our ward. We held frequent discussions with our service users to understand what their issues were, if any, and their recommendations for improvements. There was active service user presence on the ward in the form of an independent service user advocate and routine visits by a community faith representative. Training had been completed by staff on the 'recovery approach' to mental health care (see chapter 'Living at the Edge of Compromise: Balkan Pluralism as a Resource for Balanced Decision-Making"') delivered by a service user jointly with a staff member. The physical environment had also been transformed as a result of an 'Enhancing the Healing Environment' project in collaboration with a UK NGO, the Kings Fund.

At the time of the training programme there had been an increasing national focus on Black and Minority Ethnic (BME) equality in mental health. This had been prompted by several reports highlighting the lack of understanding within services of the needs of BME service users. The UK's Equality Act had also recently come into effect requiring public bodies to implement race (and other aspects of) equality in their services. All this meant that as Operational Manager responsible for the ward I wanted to build on our success by supporting the staff to feel confident delivering race equality in their everyday work. My expectation was that this would be a natural extension of our earlier work responding to service user feedback. In previous jobs I had encountered very 
defensive reactions from healthcare staff when service users questioned the established ward culture. Here by contrast staff had embraced such challenges and my expectation was that they would respond similarly to delivering race equality.

Hence my excitement when we secured funding from the UK Department of Health. Rather than just sending out a covering memo about the new corporate 'Equality policy', with instructions that it must be implemented, we now had the opportunity to provide staff with a comfortable space (the training took place in a hotel with refreshments) and time to think through what racism was and how it could be addressed on the ward.

Again, I did not anticipate any difficulties. In addition to my earlier experience of staff members' positive attitude to change, I knew them all well-my office was just off the ward area and I spent much of my time either on the ward or nearby. Yet as described further below, a key learning point for me was my surprise at just how difficult for staff the training in this area proved to be.

Evette

Since 'Empire Windrush' docked at Southampton race and equality has been a challenge for both the new-comers (British West Indians) and the host community. Both these communities were diverse in every sense, such as dress, food, and culture. Many came to work in the NHS. However, many became service users within the mental health services through compulsory admissions. With the lack of uptake voluntarily by this community and the over representation of men within all areas of mental health services, these disparities were highlighted in the publication 'Breaking the Circles of Fear', [2] after which came Delivering Race Equality' [3].

When I was approached by Kim to evaluate this project, I knew there would be challenging moments, as race equality training is never straight forward or without its challenges. But given that as Kim has described the organisation was in a good place, although I had more reservations than Kim, I too expected staff to be open to engaging positively with the challenge.

By way of background, I was told that there would be two separate training sessions, one on race equality led by an expert in this field (who was also black), and one on values-based practice led by Kim (who was already well known for her work in this area). I was introduced to members of staff to whom my role within the sessions was explained. As an evaluator I did not take part in any of the conversations or group discussions that developed during the sessions.

The race equality trainer and I were not known to each other or to the organisation. We are all female. We thus reflected the racial but not gender mix of the ward staff. The race training was very informative and as some participants expressed concerns as to the reasons why the training was on race, expressing their concerns that it would have been more helpful if It was on diversity. There clearly was a lack of understanding of what was intended by the training. Staffs' behaviour was very different when Kim (their manager) was present, they were more attentive, less confrontational and more engaging. 


\subsection{Initial Impressions}

Evette

Kim and I met after each session to reflect on the day. This allowed us to work through our own challenges. The sessions aided our focus on the original purpose of the training sessions and my role as evaluator. What I found particularly helpful was that as operational manager, Kim was very open during our discussions, at times expressing frank surprise at the behaviour I observed of some staff members, and this despite having had in some respects a very different experience of the groups from me. For some members of staff this safe space enabled them to express concerns that they had previously kept locked away perhaps even from close friends and family.

Kim

At the time I ran the values-based practice workshops I was aware that there could be challenges as people struggled to work out what the approach meant to them and in their practice. But once staff grasped the basis of valuesbased practice they were creative in seeing ways to apply it in their work.

In our sessions with ward staff the challenges became harder when the conversation turned to how they worked with each other. Here however my initial impression was that staff found the framework of values-based practice helpful in allowing them to talk about difference. This enabled some very sensitive conversations between white and black staff about their experience of working together. For example, it became apparent that what could be viewed as being abrupt was often due to having to translate what the person wanted to say from their first language to English, and vice versa. There were also what I found painful accounts of black staff being distressed by what appeared as casual comments made on the ward and white staff members having no idea that these comments had been hurtful.

An encouraging finding from our initial feedback was that all staff said they would value a regular forum, run on similar lines, where they could discuss and work through difficult issues. The session had been viewed very positively and it had been good to air some of the concerns staff had about working with each other across racial differences. Without a forum of this kind problems were likely to remain unaddressed, sometimes resulting in negative impact on staff morale and health.

\section{Evette}

The race equality training although fairly standard was challenging as it emphasised difference and how one should behave in certain situations, for example if one is being bullied, or verbally abused on account of race.

Many of the staff found some of the issues raised by the training challenging and difficult to discuss, for example issues involving behaviours and diet that were different from the norm. Comments were made such as "why should we have to change-this is our country". Those from overseas on the other hand felt that they had come to a country that they believed they understood (having grown 
up within a similar educational system). The reality they found was completely different. Black staff felt they were not supported when racially abused verbally or even physically by patients; white staff would blame this on the patients' illness as 'part of their crisis' or claim that black staff 'had a chip on their shoulder'. These are of course old clichés yet still frequently used by staff to undermine or fail to challenge inappropriate behaviours. The result is that such behaviours are all too frequently overlooked, and the victim is made to feel like the perpetrator.

Staff members, black and white, were obviously very effective in their work. The group activities however highlighted failures in their relationship across racial lines, with black staff reporting how they often went home feeling very distressed and fragmented on a personal level. One result was that when it came to activities within the group they chose people from their own background. Debate was lively within same-race groups but flowed less readily when the facilitator mixed the groups up. A noticeable if worrying finding was that the race equality trainer was quite often treated disrespectfully, with suggestions that for example that she was biased or that her facts were incorrect.

Staff also found feedback in the one-to-one interviews challenging. When the transcriptions were handed back for checking I had many comments opening with 'I did not mean...'. White staff in particular would be almost indignant to see their own words in front of them and felt they had to justify them.

The values-based practice session went a lot more smoothly. I noticed the engaged and respectful attitude staff adopted towards the trainer, i.e., Kim, as their own operational manager. Even though some of the ideas of values-based practice were unfamiliar to them they were willing to participate in the exercises without the objections or lack of enthusiasm that had thwarted the Race Equality training. Staff even managed to put some of the values-based practice training straight into practice.

I took the contrast between their reactions to the two kinds of training as showing that staff members were not resistant to change but that change would have to come on their own terms irrespective of the potential benefits for their work and personal environment.

Kim

The first I was aware that there were issues arising was when Evette mentioned that the race equality trainer was having a hard time and that she had received some very negative responses from the participants. I spoke to the trainer who as noted earlier was very experienced and an expert. They confirmed yes there were issues and they agreed to send me their feedback on the training. This feedback indicated that some white staff were not engaged with the training and were being very disruptive. Some of these staff held positions of authority in the team and therefore influenced how others responded during the training. The feedback also noted that some staff members had commented that service user racist incidents on the ward were not taken seriously and that follow-up actions were not always evident. 


\subsection{Evaluation and Report on Findings}

\section{Evette}

Four post-training focus groups were held. The groups were smaller than any of the training sessions. During the focus groups staff seem more inclined to raise issues that they had not felt able to raise before perhaps because they were afraid of the response they would receive in the larger group. I remember feeling that some of these debates would have been wonderful in the main sessions as they raised pertinent questions that the larger forum may have found useful. For example, there was much discussion about why the race equality session was focused on race and not on diversity. I noted that white participants were happier to engage in discussions around diversity than they were around race. It was almost as if the staff were intimidated to speak of race in an open and honest way. It is one of those discussion they should not be had in open for fear of saying the wrong thing. A vital opportunity was lost for open and honest dialogue between very diverse people, who as professionals went about the duties with diligence, efficiency and professionalism.

Some staff members felt that diversity rather than race quality was much more relevant to their work. Yet this was flatly contradicted by the sometimes openly disrespectful behaviour I had seen displayed in the training sessions. The atmosphere was sometimes such that I would find myself cringing inwardly at the level of disrespect shown even towards the race equality trainer and at the hostile reaction when she raised issues of race.

Kim

During the time when Evette was running the focus groups, I received concerns from a colleague involved in the project that the independent evaluator (Evette) was biased and reporting the findings in an unfair and negative way on the white staff. I checked with Evette and was reassured that verbatim accounts had been taken and shared with those taking part in the evaluation. My understanding from Evette that each participant had opportunity to double check the accuracy of the transcripts of the comments. Following this Evette submitted her findings and analysis to me and to the project group. This initial report of findings was agreed by the project group and was then used as the basis of a final project report, authored by myself and Evette and also shared with the group, that was for wider stakeholder circulation.

Through this process participants were satisfied the information contained in Evette's data collection was accurate, and the conclusions drawn in final project report were reasonable and fair. This was a journey for me where I could have used my position to override Evette's report to me, or ignored the feelings of the staff, or both to enable a less uncomfortable and more positive account of the training. However, through giving participants the opportunity and time to reflect on their accounts recorded by Evette, and by including 
participating colleagues in decisions about what was said in the final report, we were able to respect the different perspectives and achieve some difficult learning from the experience. The final project report included the following agreed conclusions:

1. There was a lower than expected level of general knowledge in relation to race equality practice. For example, an understanding of what is meant by the terms race and racism, how the service policy on racism could be implemented in practice.

2. More specifically, there was a lack of awareness/appreciation of the meaning of race as opposed to diversity or ethnicity, and its importance and effects.

3. The difficulty experienced by staff in discussing race, racial harassment and racism in a group with a mix of black and white staff could not be resolved by talking from a professional perspective alone and drew from individual's personal selves (experiences, beliefs, feelings, values).

4. The impact of racial abuse by service users towards staff whilst staff were caring form them was raised. How this should be addressed did not appear to be completely resolved or consistently addressed.

To share the learning from this experience, Evette and I, with the necessary approval, used the final project report as a basis for an article published in Mental Health Practice [1].

\subsection{Thinking Back}

Kim

Looking back on the project, I wonder how many other service areas I have spent time on with teams that have appeared to be professional, confident, and open to discussion and challenges to their custom and practice, yet where the reality was very different. If I was so unaware of the race issues within my own teams that I knew so well, surely I had been no more aware on other situations.

My concern is that without having the space to directly and personally discuss these issues, they are brushed off with oft-repeated yet contradictory assurances that, yes, we show careful attention to any race equality issues arising, and, no, there are no such issues here.

Evette

Completing the evaluation was not without its challenges for me. As a black woman, I was constantly having to dismiss my own personal feelings about some of the attitudes, misinformation and outright disrespectfulness of some members of staff during the sessions, having to remind myself of my role within the process and my own professionalism, which was to be unbiased and report only the facts. 
Ifelt that although the training in both values-based practice and Race Equality offered staff the opportunity for personal development and growth, not all staff members were receptive to this. The project highlighted not only to myself, the team and trainer that the journey through race training is not without its challenges no matter how many time you are involved, either as a black trainer, evaluator or participant, but each time you learn new ways of dealing with the situation. Values-based practice can be a very influential tool in helping to move this debate forward.

Kim

What I found hardest about the project was the extremely uncomfortable feelings I experienced, that I was somehow letting my staff down-white as well as black-when they had trusted me. I felt white staff had been hurt by being as they saw it unfairly called racist when they worked so hard to make the ward a good and caring place. I realised that black staff had also been hurt by their experiences of racism not having been taken fully seriously and acted on. I had been simply unaware of just how badly their working lives were affected by the racist treatment they experienced, even if this was described as banter or misunderstanding.

I have since learnt a lot about why white people like myself find it difficult to talk about race equality, particularly how 'judged' we can feel when discussing our own behaviour and practices.

Evette

What I find interesting is that whilst no one person was called a racist they, by their own admission, felt that their actions had led others to feel uncomfortable, and as such they themselves acknowledged that their behaviour was racist, but of course they would not call it such.

\subsection{What We Would Do Differently}

\section{Kim}

I would hold the values-based practice session before the race equality session. This would have prepared the ground by encouraging discussion about how we all have a culture within which we are embedded, one of which we are unlikely to be aware, and yet which includes assumptions and beliefs that drive own behaviour. Values based practice brings these implicit cultural values and beliefs to the fore.

Evette

Yes, the race equality training would have benefited from values-based practice. Staff would have already been exposed to the importance of implicit and explicit values and differences of values, and the challenges that diverse groups encounter particularly when people share the same working space, yet do not share or appreciate their different cultural assumptions. 
This would have had other benefits: it would have given staff the opportunity to engage with the concept of change; and it would have equipped them to acknowledge, appreciate and open their minds to alternative ways of working. As could be seen from the ward observations, were staff members were actively putting into practice some of the lessons taken from the VBP workshops.

Kim

I agree, I have searched to understand why this project was so difficult, reflecting on my position as a white person, as a values-based practice facilitator, and as a manager. I think there are many ways of understanding the concept of culture, and there are many cultures, (nursing, mental health ward, English), relevant to this experience. I wonder if one consequence of the national health service mental health ward culture is that the focus on professional accountability and the monitoring processes of clinical governance produce a culture where staff can only be seen as good or not good, with no option for a middle ground. As a staff group discussing race equality and racism on the ward, a middle ground is needed, as coming to understand and recognise racism may require some self-reflection, uncomfortable insights and painful awareness raising about ward culture and personal practice.

Evette

I firmly believe no matter how difficult this journey was for all concerned everyone would have learnt something from the experiences.

\subsection{Conclusions}

We would like to offer the below key learning points from our experience with the Race Equality and values-based practice project.

1. Be aware that being open to challenge and change in one area of healthcare (such as service user involvement) does not automatically lead to being able to be open to other challenges (race equality training). This has significant implications for understanding how cultural change works on wards.

2. The benefit of introducing values-based practice before race equality training workshops.

3. Being aware that white people find it very difficult to talk about racism.

4. Be prepared for your own position in modelling/using values-based practice when events/issues arise during training sessions.

5. Have a respectful and trusting relationship between trainers and evaluators, even if their perspectives differ.

6. Know what you are going to do if people within the evaluation strongly disagree with what you are doing, the findings and believe the trainer and the evaluator are biased.

7. Remember, there are always conflicting values, treat them all with respect. 
8. Finally, be careful about what you wish for, the aim of the project was to get staff personally engage with the training rather than just 'ticking the box' for race equality training. They really did engage. That is why it so was difficult and painful.

Acknowledgements We would like to thank all the staff that took part in the race equality and values-based practice training. They helped us learn and understand, they were often brave and sensitive when discussing difficult and challenging issues. We would also like to thank Petronella Mwasandube OBE who ran the race equality and Cultural Competence Awareness training. Finally, we are grateful to the Department of Health for funding the project through a small grant and the NHS for giving us permission to complete the study and to publish the findings.

\subsection{Guide to Further Sources}

\subsubsection{Books}

White Fragility by Robin DiAngelo published 2018 by Beacon Press. This is helpful if you are interested in understanding why white people sometimes feel very uncomfortable in race equality training. Robin DiAngelo wrote the book following her experiences in America of being a white person running race equality training and the challenging responses of white people.

Also helpful is: Between camps: nations, cultures and the allure of race. Paul Gilroy 2000. Penguin Books.

\subsubsection{Workbook}

Whose Values? A workbook for values-based practice in mental health care by Kim Woodbridge and Bill (K.W.M.) Fulford. Published in 2004, it is available as a download from valuesbasedparctice.org/More about VBP/full text downloads and scroll to training materials. Although produce a few years ago, it provides a simple and practical guide to values-based practice in mental health.

\subsubsection{Reports}

The House of commons Enforcing the Equality Act: the law and the role of the Equality and Human Rights Commission. Tenth Report of Session 2017-2019. Available from https://www.parliament.uk/business/committees/committees-a-z/ commons-select/women-and-equalities-committee/inquiries/parliament-2017/ enforcing-the-equality-act-17-19/ This gives a recent and interesting overview of policy and issues related to the Equality Acts. 
Breaking the Circles of Fear: A review of the relationship between mental health services and African and Caribbean communities https://www.centreformentalhealth.org.uk/sites/default/files/breaking_the_circles_of_fear.pdf.

\section{Reference}

1. Dodd K, Hunkins-Hutchinson E, Fulford W. Race equality training and values-based practice. Ment Health Pract. 2011;15(2):28-32.

2. Department of Health (2005) Delivering race equality in mental health care: An action plan for reform inside and outside services and the government's response to the independent inquiry into the death of David Bennett. Retrieved from http://www.dh.gov.uk/en/Publicationsandstatistics/ Publications/PublicationsPolicyAndGuidance/DH_4100773.

3. Sainsbury Centre for Mental Health (2002) Breaking the Circles of Fear: A review of the relationship between mental health services and African and Caribbean communities https://www. centreformentalhealth.org.uk/sites/default/files/breaking_the_circles_of_fear.pdf.

Open Access This chapter is licensed under the terms of the Creative Commons Attribution 4.0 International License (http://creativecommons.org/licenses/by/4.0/), which permits use, sharing, adaptation, distribution and reproduction in any medium or format, as long as you give appropriate credit to the original author(s) and the source, provide a link to the Creative Commons license and indicate if changes were made.

The images or other third party material in this chapter are included in the chapter's Creative Commons license, unless indicated otherwise in a credit line to the material. If material is not included in the chapter's Creative Commons license and your intended use is not permitted by statutory regulation or exceeds the permitted use, you will need to obtain permission directly from the copyright holder. 